\title{
Los Testimonios del culto a los reyes Amazigh en Marruecos Antiguo
}

\author{
Mohammed Said BelKassem
}

\section{Resumen}

El trabajo presenta uno de los mayores retos ante los que se enfrenta el historiador de la Antigüedad: Es el de conseguir nuevas fuentes de información para el conocimiento de la vida social y material. El tema de fondo que nos planteamos es el de contribuir a un debate determinado, el saber hasta qué punto de varias fuentes podemos deducir determinados datos válidos para un estudio sobre la divinización en Marruecos antiguo.

\section{Résumé}

Le travail présente un des plus grands défis devant ce qui s'affronte l'historien de l'antiquité: Il s'agit de parvenir des nouvelles sources des informations pour la connaissance de la vie sociale y matérielle. Le thème de fond que nous nous proposons c'est celui de contribuer à un débat déterminé, savoir jusqu'à quel point on peut déduire grâce aux divers sources pour une étude sur la divinisation au Maroc antique.

La existencia de un culto rendido a la memoria de Iuba II y Ptolomeo, como reyes de la Mauritania Tingitana, ha contribuido a la elaboración de la imagen que se volvería clásica del gran "aguelid" civilizador en esta parte del Norte de África, como es el caso de Massinisa para los númidas, rey poderoso y venerado "Massinissa aguelid et dieu", tal como es el título de un capítulo de la obra de Ch. André Julien, Histoire de l'Afrique du Nord'. Algunos autores no dudan que los reyes amazigh habían sido adorados en vida y que ellos mismos habían impuesto este culto a sus súbditos, como el caso de $\mathrm{M}$. Renatus de Lablanchére ${ }^{2}$, Ch. André Julien³, J. Carcopino $^{4}$, M. Coltelloni-Trannoy ${ }^{5}$ y H. Ghazi-Ben

1 Ch. André Julien, Histoire de l'Afrique du Nord. París, 1986, p. 99.

2 M. Renatus de Lablanchère, De rege juba regis Jubae filio. París, 1883, p. 107.

3 Ch. André Julien, Op.cit, p. 99.

4 J. Carcopino, Le Maroc antique. Paris, 1943, pp. 34-35.

5 M. Coltelloni-Trannoy, Le royaume de Maurétanie sous
Maissa $^{6}$. Si los amazigh hubieran adorado a sus reyes no sería solamente por su tendencia a la antropolatría, sino que sería también, escribe S. Gsell, por:

s'inspirant peut-être des Ptolomées, héritiers des Pharaons, Massinissa aurait jugé bon de renforcer son autorité en lui donnant un caractère divin, et ses successeurs auraient suivi son exemple"

Según las conclusiones a las cuales llegan los historiadores: los reyes mauritanos se habrían beneficiado de un culto real organizado. El rey vencedor y poderoso participa en la naturaleza divina como el caso de Alejandro, Démetrio, Ptolomeo o Augusto en Roma.

Juba II et Ptolomée (25 av. J. C - 40 ap. J. C.). Paris, 1997, pp. 194-199.

6 H. Ghazi-BenMaissa, Le culte royal en Afrique Mineur Antique. Hespéris-Tamuda, XXXV, fasc II (1997), pp. 7-42.

7 S. Gsell, Histoire ancienne de l'Afrique du Nord, París, 1930, VI, p. 132. 
Si Massinisa, Iuba II y Ptolomeo fueron dioses en vida, eso quiere decir efectivamente que los amazigh reconocían sus talentos superiores. Importaría, entonces, estudiar los elementos de este culto dirigiéndonos a la persona real y analizar los documentos que hablan de este fenómeno religioso-político, o determinar, en fin, las características reales de este culto para definir su naturaleza.

\section{LOS CONDICIONANTES HISTÓRICOS Y LOCALES.}

Hay que apuntar al principio que las circunstancias presentan considerablemente el nacimiento y el desarrollo de un culto real. El siglo II, que terminó con la llegada de Iuba al trono había visto multiplicarse en todos los Estados de Oriente y en Roma, las Apoteosis y las adoraciones de los "superhombres" vencedores de sus enemigos.

Desde el comienzo del siglo II d. C., la divinización del emperador pasó a formar parte de la realeza y pronto se extendió a las emperatrices e incluso a otros miembros de la familia imperial. El culto al emperador muerto fue, por otra parte, un excelente vínculo entre Roma, Italia y las provincias, contribuyendo así a la unidad del Imperio en una proporción nada despreciable. De esta forma se fue consolidando cada vez más la tendencia, que se remonta a la Época Helenística, del culto en vida al emperador. Oficialmente tanto Augusto como su inmediato sucesor rechazaron la divinización en vida pero aquél lo hizo en la antigua costumbre de honores al genius del pater familias ${ }^{8}$.

La época que precedió a la de Iuba II y Ptolomeo, marcó un momento decisivo en el desarrollo del culto real. Tras su muerte, los honores divinos dedicados a monarcas vivos se convirtieron casi en una costumbre, pero antes de la época de los reyes amazigh, como la de Massinisa, estos fenómenos aparecen pocas veces en las fuentes y los pocos ejemplos que tenemos, de honores divinos destinados a hombres vivos, han sido tratados con escepticismo por algunos estudiosos modernos.

No cabe duda que la tradición helenística del héroe y del rey divinizado fue un modelo a seguir. Alejandro Magno creó un precedente en la adora-

8 J. Bayet, La religión romana. Madrid, 1984, p. 193.

9 A. B. Bosworth, Alejandro Magno. Cambridge, 1996, p. 414.

${ }^{10}$ Plutarco, Alej. III, 3

$11_{\text {Heródoto, VI, 96, } 4 .}$

12 S. Lancel, Op. cit, p. 34.

13 Ibid, p. 221.

${ }^{14} \mathrm{G}$. Camps, Massinissa ou les débuts de l'histoire. Libyca. ción de un soberano como la encarnación de dios y prefiguró el culto a los gobernantes helenísticos. A principio de su reinado, se convenció de que era en cierto sentido, más que un descendiente lejano de Zeus a través de sus antepasados heroicos, y que era, el verdadero hijo del dios ${ }^{9}$. Las fuentes repiten una serie de historias sobre su nacimiento mítico ${ }^{10}$; éstas (historias) pueden haberse originado muy pronto. No era probable que se hablase de ellas en público durante el turbulento último año, cuando la legitimidad de Alejandro estuvo puesta en duda ${ }^{11}$.

En Cartago, también se puede suponer que las influencias alejandrinas relativas a las creencias, podían haber, igualmente, contribuido a estimular los antiguos recuerdos de los reyes y de los héroes. S. Lancel, ha propuesto reconocer en el relato legendario de la fundación de Cartago la transposición del rito casi universal del sacrificio del rey ${ }^{12}$. En 1947 P. Cintas $^{13}$ descubrió las primeras disposiciones del área de sacrificio, se trata de un santuario con una capilla donde se puede ver el depósito de sacrificios: esta tumba con capilla, a lo mejor, es de la fundadora de Cartago, Dido, que recibía después de su muerte el culto funerario como una diosa. Igual que el culto dirigido a los grandes dioses de Cartago: Tanit y Baal Hammon. El culto a los héroes habría tenido una cierta importancia en Cartago, independientemente del recuerdo de Dido, los cartagineses habían venerado al rey Hamilcar que fue arrojado a la hoguera del tophet ${ }^{14}$.

En Numidia, el culto a los reyes se documenta aparentemente a finales del siglo III a. C. Diez años después de la muerte de Massinisa se construyó un templo para su culto en Duga $a^{15}$, en que la dedicatoria esta en escritura púnica y en líbica, en que podemos leer:

"Les citoyens de Dougga ont bâti ce temple au roi Massinissa fils du roi Gaïa fils du Suféte Zilalsan en l'an 10 de Micipsa[...]"16.

Este dato parece indicar una divinización posterior a su muerte. Una inscripción descubierta en Cherchel-regia Iubae- que es posterior aproximadamente en medio siglo a la muerte de Micipsa, menciona el santuario en que esta dinastía habría recibido el culto real ${ }^{17}$. Estamos ante un santuario funerario dedicado "al viviente de los vivos"18.

VIII, 1960, pp. 3-320, p. 280.

15 J. B. Chabot, Recueil des inscriptions libyques. Paris, 19401941, pp. 1- 7.

${ }^{16}$ F. Decret y M. Fantar, L'Afrique du Nord dans l'antiquité. París, p. 257.

17J. G. Février, L'inscription funéraire de Micipsa. Rev. d'Assyr et d'Archéol, Orient. XLV, 1951, pp. 139-150. 
Además, mediante inscripciones en lengua latina, se documenta el culto a los siguientes reyes: Gulusa ${ }^{19}$, hijo del rey Massinisa, Hiempsal ${ }^{20}$. Una dedicatoria que lo representa como una divinidad, fue hallada en Thubursicu Numidarum ${ }^{21}$, la actual Khamisa. De las inscripciones púnicas, neopúnicas o latinas, el culto real parece haber sido dirigido a los reyes muertos por razones de orden político. Todos estos reyes eran auténticos massylos, puesto que, por su gran antepasado común, Massinisa, enlazaba su genealogía con el padre de éste, Gaïa, que TitoLivio y Apiano lo representan bajo el nombre del rey de los massylos ${ }^{22}$.

Por su parte, Sifax que era aliado de Cartago, había adoptado algunas tradiciones helenísticas como el caso de las monedas acuñadas con su efigie y de la corona que llevó a lo largo de su reinado.

Como es bien sabido, los habitantes de la Mauritania Tingitana, así como todo el norte de África, adoraban a los personajes particularmente privilegiados por la potencia o por lo sagrado que les caracterizaba. La tendencia de los mauros a la antropolatría, la baraka ${ }^{23}$ en que estaban adorando a los jefes amazigh, y todavía siguen practicando esta costumbre de forma muy profunda. El morabitismo, y su larga difusión en los países del Mogreb explica la supervivencia de la antropolatría líbica, este tipo de culto guarda siempre un carácter local, porque cada comunidad tiene sus santos. Estas personas por sus actos milagrosos atestiguan su entrada en posesión de una fuerza sagrada, por eso son reconocidos como morábitos por la voz del pueblo que transmite su santidad a sus herederos naturales o a sus elegidos. Sus fieles no les abandonan después de su muerte, permanecen cerca de su tumba, en este sentido Heródoto al hablar de los nasamones dice:

"Por otra parte, en materia de juramentos y de adivinación proceden como sigue: juran por los personajes que, entre ellos, pasan por haber sido los más ecuánimes y valientes; juran, repito, por esos personajes, poniendo la mano sobre sus tumbas" ${ }^{24}$.

Las antiguas tradiciones egipcias y helenísticas presentan condiciones favorables para enriquecer una época caracterizada por los héroes. Así, en el

${ }^{19}$ CIL, VIII, 18752.

${ }^{20}$ S. Gsell, Inscriptions latines de l'Algérie. Paris, 1957, 1242.

${ }^{21}$ F. Decret, Op. cit, p. 258 .

22 Tito-Livio, XXIV, 48, 13; Apiano, Lib, 10.

${ }^{23}$ La baraka, es enviada por Dios a los hombres como la Rahma (misericordia) y el Salam (la paz). Se podría traducir por fuerza benéfica de origen divino, que provoca una abundancia del dominio físico así como de la felicidad y la prosperidad en el orden psíquico. norte de África, los elementos estaban preparados para que la conjunción de circunstancias pudiera hacer nacer un culto real susceptible de reforzar los vínculos frágiles que unen las diferentes partes de Númidia bajo la autoridad del rey massyl. El rey amazigh buscaba una relación personal con sus súbditos, "de ahí aparecen en esta época dos fenómenos: las tribus regiani y la divinización del monarca. El primer fenómeno, no es constatado en Mauritania, pero sí en el vecino reino númida, y consiste en la existencia de tribus que tienen lazos particularmente sólidos con la realeza, de cuya relación se benefician mutuamente, en tanto que sustentan el poder real y tienen la posibilidad de enriquecerse a costa de otras tribus. El otro fenómeno, la divinización del monarca surge también en este contexto de organización no estática de sometimiento a la figura del rey"25.

Efectivamente, los testimonios de un culto dirigido a los reyes por parte de los mauros son bastante abundantes. Consisten en documentos literarios, epigráficos y, en una cierta medida, arqueológicos. Pero esta abundancia relativa esconde una pobreza de informaciones y de contradicciones que, en definitiva, hacen, para que algunos autores, duden de la realidad de este culto ¿Cuáles serían entonces estos testimonios?

\section{II- LAS FUENTES LITERARIAS.}

Muchos son los autores antiguos que han afirmado que los mauros adoraban a sus reyes, sobre todo Iuba II y Ptolomeo. Estos textos son todos posteriores a la época de Massinisa y de Iuba II ya que provienen de los autores cristianos. El documento más antiguo dice:

"Cada provincia, cada ciudad tiene su dios peculiar, como tiene Siria a Astrgale (Astrate), Arabia a Dusares el Nórico a Beleno, el África a Celestis y Mauritania a sus Régulos"26.

Minucius Felix, en Octavius, habla de un culto que aparece después de la muerte de los reyes:

"Después de su muerte, se imagina que se vuelven dios así que Iuba, por la voluntad de los mauros, fue un dios" ${ }^{27}$.

Cicerón a través Lactanio dice sobre la naturale-
${ }^{24}$ Heródoto, IV, 172.

25 F. López Pardo, Mauritania Tingitana: de mercado colonial púnico a provincia periférica romana. Madrid, 1987, p. 423.

26 Tertuliano, Apologeticus, 24, "Unicuique etiam provinciae et civitati, suus deus est, ut Syriae Astrates, ... ut Africae Caelestis, ut Mauretaniae Reguli Siu.".

27Mincius Felix, Octavius, 21, 9: "Post mortem deos fingitis, ut Iuba Mauris uolenibus deus est". 
za de los dioses:

"Se puede fácilmente comprender que en la mayoría de las ciudades el recuerdo de los hombres buenos ha sido santificado con honores divinos con fuerte corazón los peligros a favor del estado" ${ }^{28}$.

Lactancio añade a estas palabras lo siguiente:

"Con esta finalidad precisamente divinizaron los romanos a sus Césares y los mauros a sus reyes" ${ }^{29}$.

También continúa diciendo:

“[...] cada pueblo adoró con gran veneración a los fundadores de su gente o de su ciudad, ya fueran varones insignes por su fortaleza, ya mujeres admirables por su castidad: así, los egipcios a Isis; los mauros, a Iuba" ${ }^{30}$.

Algunas frases, o textos se repiten sin completar lo que los autores cristianos más antiguos nos hablan sobre el tema de la divinización entre los mauros. San Isidoro de Sevilla, dice, en este sentido, cuando habla de los dioses de los gentiles:

"Aquellos a quienes los paganos llamaron dioses se dice que en un principio fueron hombres, y que, después de su muerte, comenzaron a ser venerados entre los suyos de acuerdo con la vida y los méritos de cada uno: tal es el caso de Isis, en Egipto, de Júpiter, en Creta; de Juba, entre los moros" ${ }^{\prime 31}$.

En cuanto a Prudencio hace alusión a "las fiestas por las cuales los habitantes de Tingi conmemoran a sus reyes massylos" "32; como muestra J. Carcopino, estos reyes no pueden ser más que Iuba II y su hijo Ptolomeo como auténticos descendentes de Massinisa y de Gaïa, reyes de los massylos ${ }^{33}$. En efecto después de la entronización de Iuba, un príncipe de la familia massyl reina en Mauritania.

G. $\mathrm{Camps}^{34}$, afirma que el término mauro empleado por parte de Minucius Felix y Lactancio debe ser comprendido en un sentido amplio: no se trata solamente del pueblo de los mauros en el territorio que en el origen se encontraba entre la costa atlántica y el Muluya, sino que el reino de Mauritania estaba extendido hasta el Uadi Samam desde Bocchus. Tertuliano cita bien Mauritania, sin equivocación ${ }^{35}$.

28 Lactancio, instituciones divinas, I, 15, 6 .

29 Ibid, I, 15; 6 .

30 Lactancio, inst div, I, 15, 8 .

${ }^{31}$ San Isidoro de Sevilla, Etimologías, VIII, 11, 1.

32Prudencio, Periste phanon, IV, 45- 48: "Tingis sua (...) desta Massylum monumenta regum".

33J. Carcopino, Le Maroc antique, París, 1943, p. 286.

$34 \mathrm{G}$. Camps, Op. cit, p. 281.

35Tertuliano, Apol, 24: "Uniciuque etiam, provinciae et cuitati suus deus est ut Syriae Astrates, ut Africae caelestis, ut
Por su parte, Ibn Jaldún dice al respecto:

"Il y avait alors parmi eux (les Berbères) qui

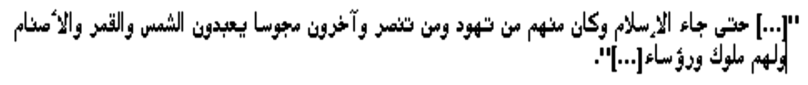

professaient la religion juive, d'autres étaient chrétiens et d'autres païens, adorateurs du soleil, de la lune et des idoles" ${ }^{{ }_{3} 6}$.

En el mismo sentido afirma El Bekri diciendo:

"Les africains dans l'antiquité furent des idolâtres dans le genre des perses, qui adorent le feu et soleil. Ils avaient de beau temples bien ornés en l'honneur de l'un et l'autre. Dans ces temples brûlait constamment un feu que l'on gardait jour et nuit pour qu'il ne s'éteint pas, de même qu'on avait coutume de la faire dans le temple de la déesse Vesta chez les Romains c'est ce que relatent tout au long les chroniques des Africains et celles des perses" ${ }^{\prime 37}$.

En realidad, estos textos no hablan de forma muy clara sobre el culto real que había predominado a lo largo de muchos siglos en tierra africana hasta la llegada de Iuba II. Minuicius Felix menciona exclusivamente un culto funerario, "Post mortem deos fingitis"; citando solamente a Iuba II como si fuera el único que se beneficiaba de este culto. Es posible que los autores cristianos no habían tenido informaciones exactas sobre la organización del culto real, tal como se presentaba dos o tres siglos antes.

No obstante, la mención exclusiva de Iuba II es bien comprensible: no podemos olvidar la fama de que disfrutó el rey Iuba II en la Antigüedad no se debió a su obra política o guerrera, sino a sus escritos $^{38}$, porque ninguno de sus numerosos libros ha llegado a nuestros días, pero se conocen varios de los títulos y fragmentos de estas obras o noticias que han pasado a formar parte del texto de algunos escritores posteriores que las usaron como fuentes informativas, sobre todo Plinio y Plutarco. Iuba II fue considerado, por los autores griegos y latinos como uno de los más grandes eruditos de su tiempo. Los romanos requerían sus servicios para preparar una expedición a Oriente ${ }^{39}$. Se puede decir que Iuba II

Mauretaniae reguli sui.",

36 Ibn Jaldún, al-'Ibar. Cairo, 1284 H, v, 8, p. 94.

${ }^{37}$ El Bekri, Op. cit, pp. 44-45.

38 Plutarco. César, 55.

39 Iuba II formó parte de los consejeros que preparan las campañas de César contra los árabes del mar rojo en el año 1 a. C. Plinio, VI, 136 y 141; XII, 56; XXXII, 10. Organiza expediciones científicas en su propio país, hacia el archipiélago de los canarias, Plinio, VI, 203. 
fue el único representante del helenismo en África, salvo Egipto. A partir, entonces, de estas condiciones no sería extraño que su nombre permanezca vivo entre los historiadores y los autores antiguos.

Estos son los testimonios literarios que hacen alusión a un culto de los reyes en África del Norte. Observamos, por tanto, que los textos más explícitos son muy tardíos, del siglo III o del IV d. C. Así Tertuliano cita los "Mauretaniae reguli" en Apologeticus. Estos autores, Tertuliano, Minucius Felix, Lactancio, son todos africanos ${ }^{40}$, por lo que no ponemos en duda sus testimonios. Se puede reconocer en sus tesis dos proposiciones: la primera, es que los reyes divinizados por los mauros son los soberanos muertos, es decir ninguno nos ha confirmado que los reyes fueron adorados en su vida. Minucius Felix, precisa, incluso, que la divinización tenía lugar "post mortem". La segunda proposición es todavía más importante para nuestro tema: todos los reyes divinizados son los "reges" o los "regulis maurorum".

Desde el siglo III d. C., la palabra mauro tiene ya en África una aceptación muy general que marca el conjunto de los africanos no romanizados ${ }^{41}$. Pero en los textos que hemos analizado, la confusión no es posible. El ejemplo que cita Minucius Felix es el caso de Iuba que se convierte en dios por la voluntad de los mauros ${ }^{42}$. Lactancio repite la misma afirmación de que los reyes fueron adorados en Tingi. Según Prudencio, se trata sin duda de Iuba II y de Ptolomeo.

Por último, tenemos que señalar que hay un curioso texto de Prudencio de origen cristiano en la Mauritania Tingitana, que nos ofrece por su parte algunos datos bastante interesantes sobre la religión indígena. El texto es lo siguiente:

\section{"Ingret Tingis sua cassianum}

\section{Festa Massulum monumenta regum}

Qui cinis gentes domitas coegit

Ad iuga christi." ${ }^{43}$.

Lo que nos interesa del texto es la relación existente entre el origen del Cristianismo en la Tingitana y la posible pervivencia del culto a los reyes. Prudencio señala, entonces, que los mauritanos de la zona de Tingi sustituían las fiestas en honor a sus reyes por la fiesta del suplicio de Casiano, y que se convertirían al Cristianismo. J. Carcopino dice en este sentido:

${ }^{40} \mathrm{G}$. Camps, Op. cit, p. 282.

${ }^{41} C f s$, G. Camps, L'inscription de Béja et le problème des Dii Mauri. Rev. Afr.XCVIII, 1954, pp. 233-260.

42 Minucius Felix, Octavius, 38; “[...] Iuba Mauris volentibus
"Prudence était donc fondé, en tout état de cause, à opposer le culte orthodoxe du saint martyr cassien au culte idolâtre rendu par les berbères à leurs princes massyles et masaesyles dans la région de Tanger" ${ }^{44}$.

Es evidente que el testimonio de Prudencio, por lo tanto, lleva signos de ser algo más que un simple discurso poético, sino un reflejo de una realidad; el Cristianismo tendría poca extensión en las ciudades de la Tingitana, propagándose fundamentalmente entre los pueblos tribales. Estos habrían mantenido el culto a los reyes como elemento religioso primordial de resistencia contra la romanización.

\section{III- LA NUMISMÁTICA.}

La numismática cada vez más se convierte en una fuente imprescindible para el estudio de la antigüedad. El hallazgo de monedas antiguas no es solamente el de una curiosidad objeto preciado de los coleccionistas. Las monedas antiguas son una valiosísima fuente documental que, en ausencia de otros testimonios, nos aportan mucha luz sobre la vida antigua. Responden a una función esencialmente económica, pero también son indiscutiblemente un testimonio histórico que nos aporta referencias fundamentales sobre aspectos políticos, comerciales, religiosos y sociales.

La moneda como objeto prestigioso también fue utilizada para otros usos y funciones de carácter muy variado. A través de ella, el poder emisor afirma su autoridad, difunde mensajes políticos y creencias religiosas, y es utilizada como un eficaz instrumento de aculturación.

Lo que nos ocupa en el estudio de las monedas acuñadas por parte de Iuba II y Ptolomeo es su iconografía como un aspecto esencial, que sirve como sello de garantía y permite entre otras cosas identificar al poder emisor. La iconografía sería elemento esencial para considerar a la moneda como un verdadero documento histórico; porque la moneda adquiere el valor de un instrumento capaz de difundir ideas e imágenes a todos sus usuarios, y símbolos de riqueza, las creencias religiosas o los dioses venerados se convierten en los mensajes más utilizados en la iconografía monetal.

La moneda tiene como función la representación del rey por intermedio de su efigie, de sus atributos, por la conmemoración de hechos ilustrados, la celebración de la paz y de la victoria. La representación 
iconográfica de la figura real da la imagen a una representación que simboliza la autoridad que de él emana. Iuba II y Ptolomeo para afirmar su divinización, han elegido varios temas en su iconografía monetal: uno deseaba integrar geográficamente y culturalmente su nuevo reino en el área griego, el otro quería mostrar la pertenencia de Mauritania al Mundo Ibero-africano ${ }^{45}$. En una moneda de Ptolomeo se ve lo siguiente:

\section{Anv. Cabeza de Ptolomeo diademada.}

Rex. Busto de caballo embridado ${ }^{46}$.

El caballo tenía un lugar muy especial en la iconografía de los pueblos norteafricanos. En Cartago ${ }^{47}$, el caballo era un símbolo solar, también empareja los atributos divinos, con el astro en forma de estrella o de rosetón, la medialuna o el globo del plenilunio $^{48}$. Entre los númidas y los mauros el sentido nacional del caballo debía preceder, en el origen, a esta dimensión religiosa. El caballo es uno de los temas más apreciados de las emisiones africanas, sobre las cuales, en todas las épocas, siempre se acompañaba de un signo astral (globo, estrella, medialuna), de la palmera o bien de signo dicho de Tanit y del Caduceo que todos afirman su dimensión sagrada $^{49}$.

Entre los elementos vegetales que aparecen en la iconografía monetal fenicio- púnica destaca la palmera que es un símbolo emblemático de Fenicia, su representación, generalmente junto al caballo, alude a Tanit. La espiga también sería uno de los motivos vegetales más utilizados, tanto en las emisiones fenicio-púnicas norteafricanas como del Sur de la Península Ibérica ${ }^{50}$, bien en su relación simbólica asociada a Tanit, la espiga perdurará como una de las tipologías principales.

La diosa Tanit es la representación iconográfica más utilizada en las emisiones monetarias cartagineses. Venerada, entre otros aspectos, como diosa guerrera o protectora de los soldados ${ }^{51}$. A través de esta iconografía Ptolomeo emitía un mensaje religiosopolítico, con el fin de identificarse con la diosa Tanit afirmando una cultura africana del poder, por una parte, y por la otra es un estilo de la iconografía monetal igual que la de los reyes helenísticos o romanos que gozaban de una autoridad divina ${ }^{52}$.

La representación más emblemática en las monedas de los reyes mauritanos y que está vinculada con el tema de la divinización, es la de Hércules que interesa sobre todo las monedas de Iuba II. La mayoría de los tipos que figuran en los reversos y que se refieren a Hércules se caracterizan en la iconografía del templo, de adornos triunfales, elefante, cuernos y delfín.

Como ha quedado dicho, Iuba II hizo enlazar su genealogía con Hércules. En realidad, como es sabido, Iuba II descendía de Massinisa a través de Micipsa, Adherbal, Jugurta, Hiempsa e Iuba I, pero prefería enlazar su genealogía con orígenes divinos y heroicos, en concreto con Hércules, para lograr así reforzar políticamente su reino sobre los territorios de la Mauritania Tingitana. Plutarco señala que según los tingitanos, a la muerte de Anteo, la mujer de éste, Tingi, tuvo de Hércules un hijo llamado Sofax que habría reinado en el país y habría puesto a la ciudad Tingi el nombre de su madre. A Sofax le sucedería su hijo Diodoro que según la tradición habría dirigido un ejército griego compuesto por los trasladados allí por Hércules desde Micenas. Plutarco concluye al respecto: "Pero todo esto sea dicho en honor de Iuba, el mejor historiador entre los reyes, ya que se dice que su linaje traía origen de Diodoro y Sophax" ${ }^{153}$. En fin se puede señalar que el nombre mismo de Diodoro legendario es una traducción griega de un nombre púnico Muttunba'al; que remite a Baal. Ahora bien, Hércules era el hijo de Zeus, a lo mejor Iuba II quería recordar en su genealogía su ascendencia prestigiosa relacionada con Hércules ${ }^{54}$.

La mayoría de los temas representados en las monedas de Iuba II aspiraban a legitimar su poder a través de la genealogía divina, como las victorias ${ }^{55}$, pero sobre todo a través de la piel del león y de elefante. En las monedas $n^{\circ} 176$ hasta 188 se puede leer lo siguiente:

Anv, Rex Iuba (Ley, der), busto del rey deademado con clava a la derecha. Gráfila.

${ }^{45}$ M. Coltelloni-Trannoy, Op. cit, p. 172.

46. Mazard, Corpus Nummorum Numidiae Mauretanique. París, $1955, \mathrm{n}^{\circ}, 407$.

${ }^{47}$ L. Müller, Numismatique de l'ancienne Afrique. II, Bologna, Italia, sin fecha, p. 74

${ }^{48}$ C. Cabrerizo Garcia, Monedas de Numidia y Mauritania. $N$. H. X, 1961, pp. 103- 122.

49 Mazard. (J), n ${ }^{\circ}, 57,64,65,70,112,113,117,158,160 ;$; 515516- 522.; Mûller, Op. cit, n' , 122, 126, 256, 299.

50 T. Marot, Introducción a la numismática antigua: El ejemplo de la moneda en el mundo púnico. VII, jornadas de Arqueología fenicio-púnica. Ibiza, 1992, pp. 9-25, p.20.

${ }^{51} C f s$, L. Manfredi, Riconiazione ed errori di conio nel mondo punico. Supplemento della Rivista di Studi Fenici. XVIII, 1990, pp. 11-18.

52 J. Babelon, Les monnaies racontent l'histoire. 1963, p. 36 y 47.

53 Plutarco, Sert, IX.

54 L. Müller, Op. cit, p. 118; J. Mazard, Op. cit, p. 72.

55 Ibid, n ${ }^{\circ}, 196-197$ hasta 203. 
Rev, piel del león de Nema, colgante una clava, a la izquierda una flecha, a la derecha, un arco. Gráfila.

Hay que recordar en este caso que los reyes helenísticos conservan en el anverso de sus monedas el retrato de Alejandro con los cuernos de Amón. El cuero cabelludo de elefante o la piel de león de Hércules $^{56}$, son una alusión clara a la divinización de Alejandro y su identificación con el héroe griego. Este había sido el prototipo de los retratos de todos los soberanos divinizados como Iuba II. Por eso, vemos en una moneda de Iuba II n ${ }^{\circ} 296$ a la derecha: REX IVBA, busto del rey cubierto por la piel de elefante, a la izquierda, detrás de dos jabalinas todo en una corona de palmeras. Al reverso hay una águila con alas desplegadas, teniendo un cetro adornado con flores, todo inscrito en una corona cerrada de laurel.

Por otra parte en las monedas $n^{\circ} 260$ a 264, figuran el busto de Iuba II con piel de león, en el reverso un delfín que lleva una corona remitiendo a Hércules, porque el delfín está relacionado con el culto a Hércules-Melqart y con un sentido funerario o de amuleto relacionado con la prosperidad, y disfruta de una posición destacada en las representaciones, tanto del Mundo Fenicio-púnico como Griego ${ }^{57}$.

Ya hemos adelantado que los reyes mauritanos, Iuba II y Ptolomeo querían seguir el mismo camino de los emperadores romanos y helenísticos. Respecto a su sucesor, Augusto consideraba a Hércules como una deidad oficial romana, con quien aparece en acuñaciones monetarias. Hay monedas gaditanas con el frontis del templo rodeado de laurel en el reverso y un haz de rayos con la leyenda AVGVSTVS DIVIF en el anverso ${ }^{58}$. Otra de

56 C. Préaux, El mundo helenístico, Grecia y Oriente. Tomo, I, Barcelona, 1984, p. 76.

57 T. Marot, Op. cit, p. 20

58 Véase, principalmente M. Guadán, Las monedas de Gades. Barcelona, 1963.

59 A. Garcia y Bellido, Hercules Gaditanus. Archivo Español de Arqueología. XXXVI, 1963, pp. 70-153, p. 137.

60Plinio, IV, 119.

61 M. Leglay, Mythes, légendes et réalités cultuelles. Latomus. XLVIII, 1989, pp. 581-589, p. 586.

62 Iuba II apartaba así Amón, como una gran divinidad africana y oriental que evocaba directamente la persona de Alejandro Magno y que su padre Iuba I había elegido de representar en algunas monedas, C.N.N.M. $\mathrm{n}^{\circ} .90$ y 92 . Durante el periodo del interregno una moneda lleva esta figura emblemática del poder real: $\mathrm{n}^{\circ} .18$ a 72 .

63 J. Bayet, Op. cit, p. 190. las acuñaciones gaditanas nos muestra en el anverso la efigie laureada de Augusto con la leyenda AVGVSTVS, y en el reverso el mismo frontis del templo rodeado de láurea, como en la moneda anterior. A. Garcia y Bellido en su estudio sobre Hércules gaditano ${ }^{59}$, afirma que Cádiz recibió el título de Muncipium Augustum Gaditanum por la asimilación de Augusto y el Hércules gaditano, por su parte Plinio $^{60}$, llama a Cádiz Augustana por el mismo motivo. Pues con el principado, "l'héros grec va devenir à la fois un héros, mieux un dieu national et un symbole augustèen" ${ }^{\circ 1}$.

La elección de Iuba II tenía como ventaja vincular la dinastía mauritana a una divinidad líbica ${ }^{62}$ a la cual el rey se ocupaba de dar una buena apariencia en Roma, porque es en esta época y en contra del discurso propagandístico oficial ${ }^{63}$ que los admiradores de Augusto eligieron a Hércules como figura emblemática del princeps $^{64}$ : autor de la paz, constructor de ciudades Hércules, entonces, resumía en su persona las cualidades fundamentales del emperador.

La figura simbólica de Hércules elegida por Iuba II para representar en sus monedas la persona real, el rey mauritano se servía de la muy antigua devoción que los pueblos norteafricanos dirigían al dios Hércules llegado desde el Oriente para instalarse entre ellos, las leyendas la vinculan a algunas ciudades africanas, sus lugares del culto se extendían a lo largo de las orillas del Atlántico, haciendo frente al gran santuario de Gades, su nombre, incluso marcaba la topografía del país. Es a partir de la difusión del culto heracleo y de relatos contados por los antiguos sobre la genealogía mítica de los amazigh a través del enlace de Iuba II a Hércules ${ }^{65}$ que se elabora una verdadera dinastía heracleana, en la que

${ }^{64}$ Horacio, Odes, III, 1- 4.

${ }^{65}$ La fundación de Tingi, (Plutarco, Sert, 9, 8- 10; Mela, I, 5 y III, 9; Plinio, V, 2), habría sido debida a Hércules que había cumplido uno de sus doce legendarios trabajos en Lixus (Plinio, V, 3); un altar a Hércules (Plinio, V, 4) ocupaba una isla del estuario de Lixus; una gruta en cabo Espartel está consagrada a (Mela, 1, 5) y Ptolomeo sitúa en el Sur de Sala un cabo de Hércules, hoy día es identificado al Ras-El Hadid (Ptolomeo, IV, 1, 2). Por el conjunto de los indicios que revelan el culto de Hércules en la Mauritania Tingitana, $C f s$, R. Rebuffat, Bronzes antiques d'Hercules trouvés à Tanger et Azila. Ant. Afr. V, 1971, pp. 179- 191. En efecto, las regiones donde el culto dirigido a Hércules eran las regiones de fuerte punicización: así Lixus (C N N M , nº, 465-468) Shemes (J. Marion, Monnaies de Shemesh et des villes autonomes de Maurétanie Tingitane du musée Louis- Chatelain à Rabat. Ant. Afr. VI, 1972, pp. 59-128. 
Iuba II y su hijo se representaron como herederos directos y legítimos de los reyes mauritanos, massylos y masaesylos ${ }^{66}$.

De modo diferente a su padre, Ptolomeo, no contento con este origen divino por vía paterna, se lo fabricó también por vía materna. Como es sabido era hijo de Cleopatra Selene y, por lo tanto nieto de Cleopatra de Egipto ${ }^{67}$. Nadie puede negar la divinización de la reina Cleopatra porque la tenemos atestiguada en varios retratos de la reina lágida. Los soberanos de las monarquías orientales no fueron adorados como dioses, por su parte las reinas participaban en los honores cultuales que otorgaban las ciudades. Tanto después de su muerte como en su vida fueron asimiladas, por medio de los epítetos, a Afrodita y, más tarde a Isis ${ }^{68}$ siendo además asociadas al culto de estas diosas. Esta práctica está profusamente atestiguada entre los Lágidas y en otras dinastías.

El variado simbolismo religioso egipcio de la ceca mauritana de esta época incluye las imágenes del cocodrilo ${ }^{69}$, del Ibis $^{70}$ y del hipopótamo ${ }^{71}$ asociados a los dioses Sobek, Tot y Tueris, respectivamente, así como diversos atributos o figuras isíacas, tales como el disco solar entre cuernos de vaca. Todas estas iconografías demuestran la fidelidad de la madre de Ptolomeo, Cleopatra Selene, hacia las creencias de su país de origen. Estas figuras zoomorfas encontradas en Banasa $^{72}$ y en Volubilis $^{73}$, pueden ayudar a perfilar la idea de la divinización de la reina, basada en las acuñaciones monetarias de su época, su imagen o su nombre escrito en griego ${ }^{74}$ aparece invariablemente acompañado a los de su marido en los abundantes testimonios numismáticos. Tenemos una única moneda de la reina lágida, que está en el museo de las antigüedades de Rabat, donde se puede ver una muestra de la deificación de Cleopatra Selene: se ve a la derecha REX IVBA; busto de Iuba deadimado, en el reverso el nombre de la reina en griego y una pequeña serpiente enderezada al centro, debajo símbolo de Isis, a la izquierda un pequeño creciente. Según J. Mazard la serpiente con Isis debajo es una alusión clara a la divinización de la reina ${ }^{75}$.

${ }^{66}$ Veáse P. Corbier, Hercule africain, Divinité indigène? D. H. A. I, 1974, pp. 95-104; y M. Clavel-Lévêque, À propos de l'Hercule africain: Réflexions sur les modes de syncrétisme. D. H. A. I, 1974, pp. 105-107.

67 Estrabón, XVII, 3, 7; Suetonio, Calígula, XXVI.

${ }^{68}$ C. Préaux, Op. cit, p. 57.

$69_{\text {J. Mazard, }} \mathrm{n}^{\mathrm{o}}, 331-346$.

70 Ibid, $\mathrm{n}^{\circ}, 331$ a 338 .

71 Ibid, n ${ }^{\circ}, 347$.
Se puede pensar, por supuesto, que la semejanza entre Selene y su madre habría podido conducir hacer un retrato de la mujer de Iuba II, dándola el aspecto hierático, la reina de Egipto, como el caso del retrato de Cherchel, J. Baradez señala que:

"S'agit-il seulement pour Sèlené de montrer son culte filial et dynastique envers la grande Cleopâtre? Ou s'agit- il du désir du jeune couple de tout faire pour rappeler non seulement à ses sujets, mais à Rome que leur fils auquel sera donné le nom de Ptolaemeus, appartient bien à la race des lagides et descend des rois grecs d'Égypte?"ך.

Así, que la ascendencia real y divina de Ptolomeo queda demostrada y admitida, lo que conduce a Calígula a acabar con el joven rey mauritano.

\section{Bibliografía:}

ANDRÉ JULIEN. CH.

Histoire de l'Afrique du Nord. París, 1986.

BABELON. J.

Les monnaies racontent l'histoire. Ed, Fayed, 1963.

BARADEZ. J.

Un grand bronze de Juba II témoin de l'ascendance mythique de Ptoémée de Maurètanie. Bulletin d'archéologie du Maroc. IV, 1960, pp. 117-132.

BAYET. J.

Les origines de l'Hercules Romain. París, 1926.

La religión romana. Madrid. 1984.

BOSWORTH. A.

Alejandro Magno. Cambridge, 1996.

Cabrerizo Garcia. C.

Monedas de Numidia y Memorias de Historia Antigua, 1961, pp. 103-122.

CAMPS. G.

L'inscription de Béja et le problème des Dii

72 R. Thouvenot, Une colonie romaine de Maurétanie Tingitane: Valentia Banasa. Paris, 1941, p. 91.

${ }^{73}$ A. Jodin, Statuettes de tradition phénicienne trouvées au Maroc. B. A. M. IV, 1960, pp. 427-435.

74 J. Mazard, n', $297-325$.

75 Ibid, n ${ }^{\circ}, 298$.

76 J. Baradez, Un grand bronze de Juba II témoin de l'ascendance mythique de Ptolémée de Maurètanie. 
Mauri. Revue Africaine. XCVIII, 1954, pp. 233260.

Massinissa ou les débuts de l'histoire. Libyca. VIII, 1960, pp. 3-320.

CARCopino. J.

Le Maroc antique. París, 1943.

Clavel-LévêQue. M.

À propos de l'Hercule africain: Réflexions sur les modes de syncrétisme. Dialogues d'Histoire Ancienne. I, 1974, pp. 105-107.

Coltelloni-Trannoy. M.

Le royaume de Maurétanie sous Juba II et Ptolomée (25 av. J. C-40 ap. J. C.). París, 1997.

CORBIER. P.

Hercule africain, Divinité indigène? Dialogues d'Histoire Ancienne. I, 1974, pp. 95-104.

DECRET. F y FANTAR. M.

L'Afrique du Nord dans l'antiquité. París, 1981.

FÉVRIER. J. G.

L'inscription funéraire de Micipsa. Rev. D'Assyr et d'Archéol, Orient. XLV, 1951, pp. 139-150.

GHAZI-BEn MAissa. M.

Le culte royal en Afrique Mineur Antique. Hespéris-Tamuda, XXXV, fac2, 1997.

Снавот. J. B.

Recueil des inscriptions libyques. París, 19401941.

Garcia. A y Bellido.

Hercules Gaditanus. Archivo Español de Arqueología.

XXXVI, 1963, pp. 70-153.

GSELL. S.

Inscriptions latines de l'Algérie. París, 1957.

Histoire ancienne de l'Afrique du Nord. París, 1930.

\section{GuAdÁN. M.}

Las monedas de Gades. Barcelona, 1963.

Jodin. A.

Statuettes de tradition phénicienne trouvées au Maroc. B. A. M. IV, 1960, pp. 427-435.

LANCEL. S.

Cartago. Barcelona, 1994.

LEGLAY. M.
Mythes, légendes et réalités cultuelles. Latomus, XLVIII, 1989, pp. 581-589.

LÓPEZ PARDO. F.

Mauritania Tingitana: de mercado colonial púnico a provinvia periférica romana. Madrid, 1987.

MANFREDI. L.

Riconiazione ed errori di conio nel mondo punico. Supplemento della Rivista di Studi Fenici. XVIII, 1990, pp. 11-18.

MARION. J.

Monnaies des Shemesh et des villes autonomes de Maurétanie Tingitane du musée LouisChatelain à Rabat. Antiquité Africaine. VI, 1972, pp. 59-128.

MAROT. T.

Introducción a la numismática antigua: El ejemplo de la moneda en el mundo púnico. VII, jornadas de Arqueología fenicio-púnica. Ibiza, 1992, pp. 9-25.

MAZARD. J.

Corpus Nummorum Numidae Mauretanique. París, 1955.

MÜLLER. L.

Numismatique de l'ancienne Afrique. II, Bologna, Italia, sin fecha.

PrÉAux. C.

El mundo helenístico, Grecia y Oriente. Tomo, I, Barcelona, 1984.

REBUfFAT. R.

Bronzes antiques d'Hercules trouvés à Tanger et Azila. Ant. Afr. V, 1971, pp. 179-191.

Renatus de Lablanchére. M.

De rege juba regis Jubae filio. París, 1883.

THOUVENOT. R.

Une colonie romaine de Maurétanie Tingitane:

Valentia Banasa. París, 1941.

Fuentes Literarias.

APIANO

Historia Romana, 10

Dio CASIO.

Historias Romanas, XVII.

HERÓDOTO.

Historias, IV, 172. 
HORACIO.

Odes, III, 1, 4.

IBN JALDÚN

AlIbar, V, 8.

JUSTINO

Cornelius Nep, XI.

LACTANCIO.

Instituciones divinas.

MEla.

Geografía, 1,5. III.

Minucius Felix.

Octavius, 38.

Plinio.

Historia Natural, V, 2.

Plutarco.

Vida parálela. Alej, III, 3- XXVII, 5-8. César, 55. Sert, IX.

PRUDENCIO

Periste-Phanon, IV, 45-48.

SAN IsIDRO DE SEVILla.

Etimologías, VIII, 11, 1.

Tertuliano

Apologeticus, 24.

Tito-Livio.

Historia Romana, XXIV, 48, 13. 